\title{
Review \\ Bench-to-bedside review: Ventilatory abnormalities in sepsis
}

\author{
Sheldon Magder
}

McGill University Health Centre, Division of Critical Care, Department of Medicine, Pine Avenue W, Montreal, Quebec, H3A 1A1, Canada

Corresponding author: Sheldon Magder, Sheldon.magder@mcgill.ca

Published: 15 January 2009

This article is online at http://ccforum.com/content/13/1/202

(c) 2009 BioMed Central Ltd
Critical Care 2009, 13:202 (doi:10.1186/cc7116)

usually is increased [10]. If the increase in ventilation in sepsis were just a response to increased metabolic demands with an increase in oxygen consumption and production of carbon dioxide, then the partial pressure of carbon dioxide $\left(\mathrm{PCO}_{2}\right)$ would not change, but it often decreases. It is also not simply compensation for a metabolic acidosis because the $\mathrm{pH}$ in the early stages of sepsis is often above 7.4 [11]. Thus, the increase in ventilation is a primary event and represents hyperventilation (ventilation beyond metabolic needs), and a respiratory alkalosis in a critically ill patient should always raise suspicion of a generalized inflammatory response.

The specific cause of increased respiratory drive is not known but cytokines such IL-1 $\beta$ and IL- 6 are likely factors. Another factor is the role played by peripheral afferent nerve fibres [12] (Figure 1). Vagal afferents exist in the periphery of the lung that initiate a marked increase in efferent phrenic nerve activity when the endings of these afferents are stimulated with simple injections of hypertonic saline [13]. Another reflex response comes from thin fibre afferents in the diaphragm and other respiratory muscles [14].

All muscles have thin afferent fibres (type III and type IV nonmylenated fibres) that respond to mechanical stimuli as well as noxious metabolic signals such as arachidonic acid metabolites, increased potassium ions, increased osmolality and lactate $[15,16]$, and they act on the ventilator area of the brain stem to increase ventilation and, in particular, respiratory frequency [17]. Activation of these afferents in the diaphragm can result in an important positive feedback loop, especially in someone with lung disease. The consequent increased drive to breathe increases the energy consumption of the diaphragm, which thus increases metabolites in the diaphragm that further increase the respiratory drive, so that the process feeds on itself until ventilator muscle failure occurs. Activation of these afferents also results in increased activation of the sympathetic nervous system, with conse-

$\mathrm{FOXO}=$ forkhead box $\mathrm{O} ; \mathrm{IL}=$ interleukin; $\mathrm{NO}=$ nitric oxide; $\mathrm{NOS}=$ nitric oxide synthase; $\mathrm{PCO}_{2}=$ partial pressure of carbon dioxide; $\mathrm{PEEP}=$ positive end-expiratory pressure; $\mathrm{PTI}=$ pressure-time index; ROS = reactive oxygen species; TNF = tumour necrosis factor. 


\section{Figure 1}

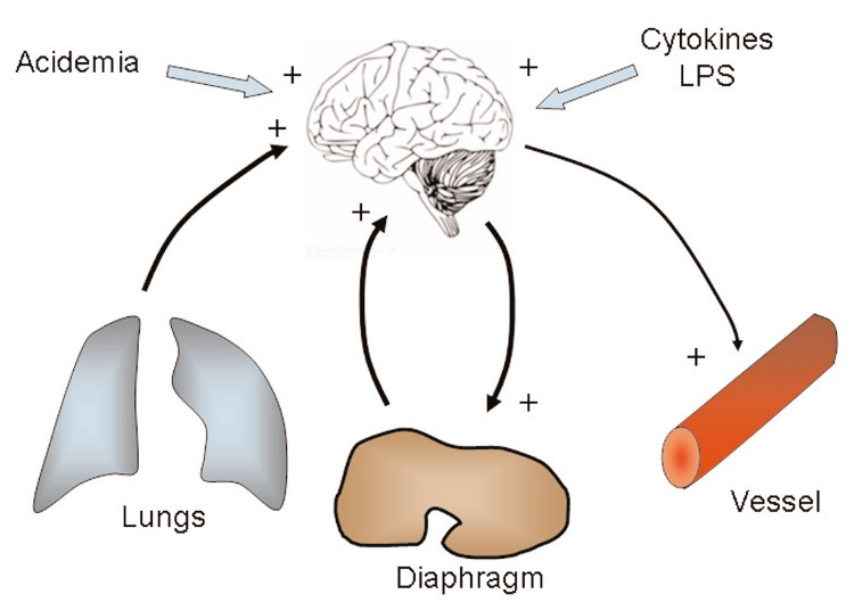

Schema of factors involved in increased ventilatory drive. Cytokines, endotoxin (LPS) and acidaemia produce an initial increase in the drive to breathe. Demands on the ventilatory muscles (especially the diaphgram) are also increased by a decrease in dynamic compliance of the lungs and chest wall. Increased metabolic activity in ventilatory muscles activates type III and IV afferents, which further increase the drive to breathe. Lung injury activates vagal afferents that also increase respiratory drive. Efferent activity from the brain increases sympathetic activity, which can lead to vasoconstriction and increased heart rate. See text for further details. LPS, lipopolysaccharide.

quent increases in heart rate and peripheral vasoconstriction [18]. The increased ventilatory drive is suppressed by narcotics but does not respond very well to benzodiazepines, which is consistent with increased drive of a central ventilatory pacemaker site.

\section{Abnormalities of the ventilatory pump}

Failure of the ventilatory pump is a central component of severe sepsis and a major cause of death in sepsis [1]. In animals treated with lipopolysaccharide (endotoxin), ventilatory failure leads to death before circulatory failure if ventilation is not supported $[19,20]$ (Figure 2). The pattern is similar to what is seen in other forms of shock [21-23]. There is a period of increased ventilation and increased respiratory work, and then a decline in force generation by the respiratory muscles, and eventually respiratory arrest. Importantly, $\mathrm{PCO}_{2}$ does not usually rise until the animals become apnoeic [24]. The same pattern most often occurs in patients. Thus, impending ventilatory failure must be anticipated and acted upon before $\mathrm{PCO}_{2}$ increases. The decision to provide mechanical ventilatory support should be based on a pattern of progressively increasing rate of breathing with falling tidal volumes (rapid-shallow breathing) and respiratory distress.

When considering the mechanisms, one must consider problems related to increased ventilatory muscle energy demands, decreased supply of energy to the ventilatory muscles and decreased intrinsic muscle function.

\section{Increased energy demands}

The energy needs of the ventilatory system are determined by the tension produced by the respiratory muscles per minute. Normally, expiration is passive and active expiration is only required during heavy exercise, so that it is the energy demands on inspiratory muscles that are the primary determinant of ventilatory failure. The diaphragm is the major muscle for inspiration and the key to understanding ventilatory failure in sepsis; intercostal muscles also play a role in inspiration but to a lesser extent. Importantly, it is not respiratory work - the product of pressure and volume - but tension that is the key determinant of diaphragmatic energy needs. This situation is identical to that of the heart, in which tension and not work determines cardiac energy needs [25].

The tension in the diaphragm is related to the pressure across the diaphragm, the fraction of the cycle spent in the contraction phase (duty cycle) and the number of contractions per minute (respiratory rate). A value called the 'pressure-time index' (PTI $\left[\mathrm{CmH}_{2} \mathrm{O} \times\right.$ second/minute]) can be calculated from the product of the transdiaphramatic pressure (abdominal pressure - pleural pressure $\left[\mathrm{cmH}_{2} \mathrm{O}\right]$ ) and inspiratory time (seconds), and divided by respiratory frequency (breaths/ minute) [24]. An increase in the ventilatory rate thus increases the energy demand because it results in more time per minute in the contraction phase. However, based on measurements of diaphragmatic blood flow in animals, a large part of the increase in diaphragmatic energy demands that occurs with an increase in frequency is independent of the total pressure per time [26]. This is thought to occur because there is an 'activation' energy required to initiate each contraction. The duty cycle (fraction of time in the contraction phase) usually remains constant with increases in frequency of contractions, which means that the inspiratory time decreases with increases in rate. Thus, a constant tidal volume at an increased rate requires faster inspiratory flow rates to achieve the tidal volume. This can significantly increase airway resistance, especially in those breathing through an endotracheal tube because of the exponential pressure-flow relationship of these tubes. The sum of these effects means that increased respiratory rate greatly increases the energy demands of the diaphragm [27] and explains why rapid-shallow breathing is such a strong predictor of ventilator failure. It has also been shown that an increase in transdiaphragmatic pressure produced by a negative pleural pressure is more energy costly for the diaphragm than transdiaphragmatic pressure produced by increasing abdominal pressure [28].

The pressure required to achieve a tidal breath is related to the airway resistance (and resistance through the external circuit if the patient is intubated), the elastance (inverse of compliance) of the lungs and chest wall, and the presence of any threshold load, which occurs when there is positive endexpiratory pressure (PEEP), whether this PEEP is intrinsic (auto-PEEP) or extrinsic. In animals in which lung injury has been produced with oleic acid there is a large fall in dynamic 


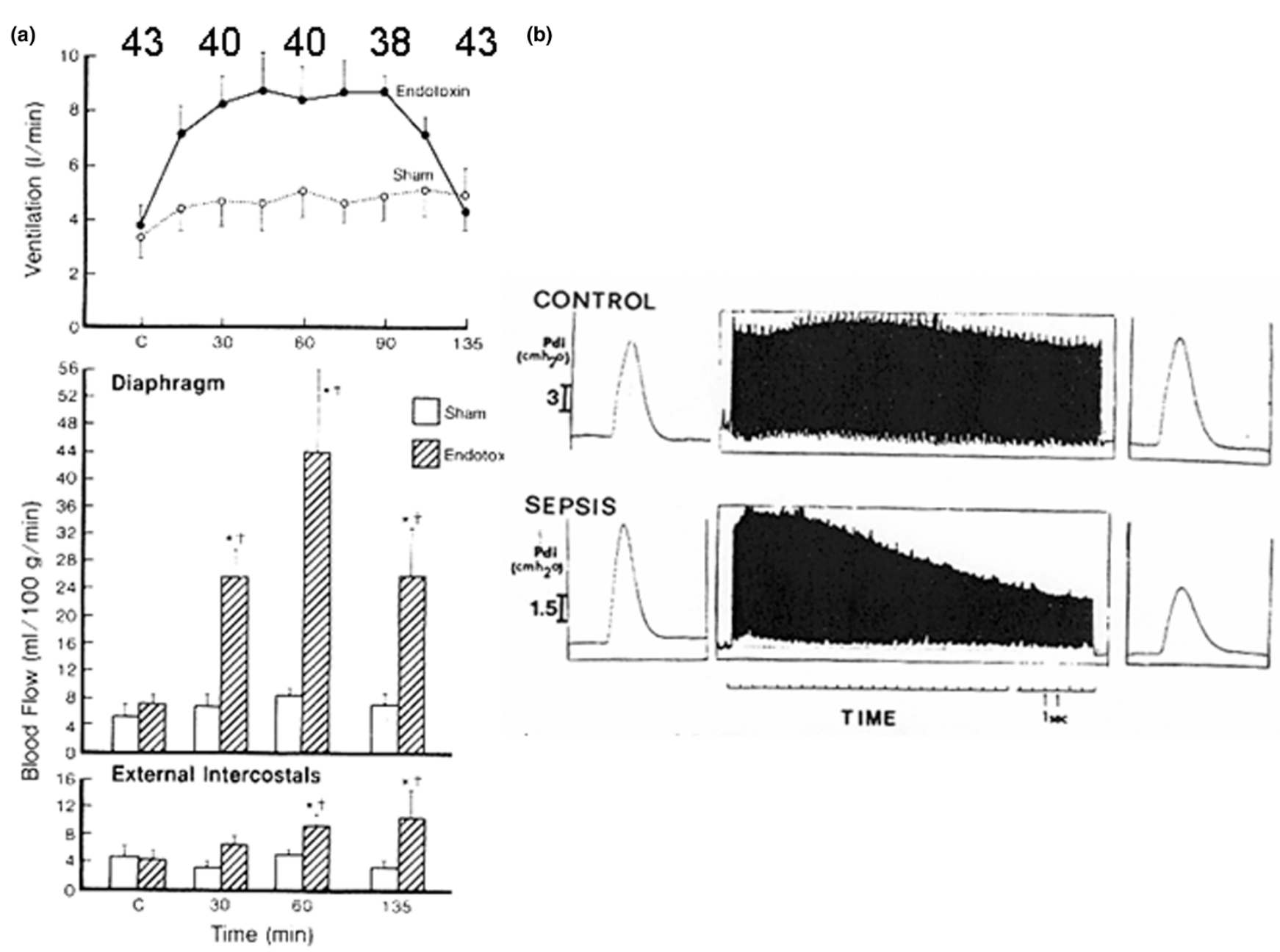

(a) The top part of the figure shows the endotoxin induced increase in ventilation in dogs, which then decreases as the animal's ventilatory muscles fail. The numbers at the top represent the mean values for $\mathrm{PcO}_{2}$ in septic animals at each stage. Note how stable they remain, even with decreasing ventilation. The bottom shows the changes in diaphragmatic and intercostal muscle flows that were associated with the changes in ventilation. Reproduced with permission from Hussain and coworkers [24]. (b) An example of the loss of diaphragmatic endurance in rats treated for 3 days with Streptococcus pneumoniae. After 3 days phrenic nerves were stimulated at $10 \mathrm{~Hz}$ for 30 seconds and transdiaphragmatic pressure (Pdi) was measured. Single twitches are shown at the beginning and end of 30 seconds of stimulation. There was a marked decrease in tension in septic animals compared with controls. Reproduced with permission from Boczkowski and coworkers [68].

compliance, which is related to all three types of loads [29]. It is likely that a large part of this load is related to airway closure, and airway recruitment on inspiration is probably a more important contributor to the threshold load than changes in elastance of lung tissue [30]. It has also been shown that in the initial stages of oleic acid induced lung injury, chest wall compliance does not change [31]. However, in the clinical setting, in which large amounts of fluids are often used for resuscitation, or when abdominal pressure is increased, as in patients with peritonitis, decreased chest wall compliance can become very important [32,33].

Increased load on the ventilatory system means that the diaphragm must generate greater tension to generate a breath. As the lung injury progresses physiological dead-space also increases, so that ventilation must increase further to compensate and maintain a normal $\mathrm{PCO}_{2}$ [34]. From an energetic point of view, an increase in elastic load is best dealt with by breathing at a rapid rate and small tidal volume, because the smaller peak pressure required for a smaller tidal volume minimizes the PTI [35]. The increased rate actually occurs naturally because of factors that increase the drive to breathe, as discussed above. However, the shallow breaths eventually result in progressive atelectasis and the person increasingly breathes around the lower inflection point, which further increases the respiratory load. With progressive failure of the ventilator pump, hypoxaemia and acidaemia develop, which lead to a further decline in ventilator pump function and respiratory failure. 

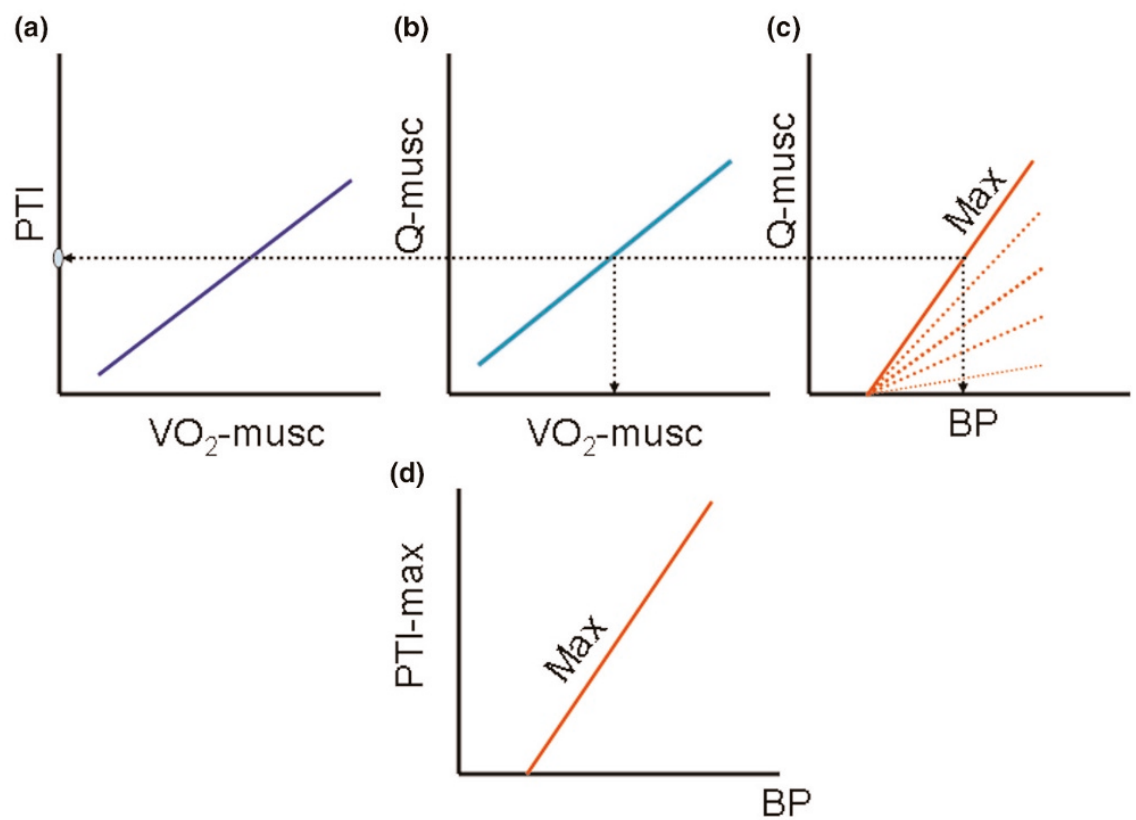

The relationships of diaphragmatic PTI, oxygen consumption, blood flow and arterial blood pressure. (a) The linear relationship between PTI and oxygen consumption. (b) The linear relationship between oxygen consumption and blood flow, which is seen in all muscles. (c) The pressure flow lines for different vascular conductances (1/resistance). The steepest line indicates maximum conductance (minimum resistance) and thus the highest possible flow for any given blood pressure. (d) Maximum PTI is determined by the maximum flow at a given blood pressure. The dotted line in panels a to $\mathrm{c}$ shows the maximum flow for that blood pressure that gives the maximum oxygen consumption for that blood pressure, and therefore the maximum sustainable PTI for that blood pressure. BP, blood pressure; PTI, pressure time index; Q-musc, blood flow; VO ${ }_{2}$-musc, oxygen consumption.

Although the above discussion is sufficient to explain the ventilator failure of sepsis, it is unlikely that increased ventilator demands solely account for ventilator muscle failure. The ventilatory system has large reserves. At peak exercise total ventilation in a $75 \mathrm{~kg}$ man can reach over $150 \mathrm{l} / \mathrm{minute}$, and total ventilation of 40 to $50 \mathrm{l} /$ minute can be maintained by marathon runners for prolonged periods of time. What, then, is different in the septic patient?

\section{Decreased supply of energy}

In the early phase of sepsis limitation in blood flow and energy supply probably play the major roles, because the pattern of diaphragmatic failure is similar to that observed in other types of shock [20-22,36,37]. Sustained muscle function requires oxygen, so that oxygen delivery is a critical determinant of diaphragmatic function (Figure 3). Oxygen delivery is determined by blood flow, the concentration of haemoglobin and its saturation, which in turn is determined by the partial pressure of oxygen. Blood flow is determined by arterial pressure minus the downstream pressure divided by the resistance to flow in the tissue. In shock of any type there is, by definition, a fall in arterial pressure, which compromises flow. This can be compensated for to some extent by vasodilatation and a decrease in local arterial resistance, but once vasodilatory reserves are used up flow becomes totally dependent upon arterial pressure [38,39]. Knowledge of the lowest resistance of the vasculature of the diaphragm gives an indication of the highest flow possible at a given pressure, which accordingly indicates the maximum possible sustainable work by the diaphragm. We previously calculated the maximum vascular conductance in the diaphragm of dogs to be $3.13 \pm 0.56 \mathrm{ml} /$ minute per $\mathrm{mmHg}$ per $100 \mathrm{~g}$ and the pressure at zero flow to be $17 \mathrm{mmHg}$ [39]. It has been shown that the relationship of blood pressure to diaphragmatic flow is just about at this limit in dogs with septic shock [36] as well as in dogs in cardiogenic shock and with increased pulmonary elastance to simulate pulmonary oedema [23]. This supports the argument that a limitation in oxygen delivery to the ventilatory muscles is an important factor in the ventilator failure observed in the early stages of sepsis.

Of importance, diaphragmatic blood flow and oxygen delivery to the diaphragm are dependent upon arterial pressure and not cardiac output, although the cardiac output along with the total peripheral resistance determine arterial pressure $[40,41]$. Severe reductions in cardiac output can result in reflex vasoconstriction, which could overcome local metabolic signals in the diaphragm, increase the diaphragmatic vascular resis- 
tance and decrease diaphragmatic blood flow. Similarly, high doses of vasoconstrictors such as norepinephrine (noradrenaline) can compromise diaphragmatic flow [42]. On the other hand, profound hypotension due to a generalized loss of vascular tone, even with high values of cardiac output, can result in inadequate diaphragmatic blood flow. Under this condition the excess blood flow is effectively shunted through sites of low metabolism, and it is possible that restoring some vascular tone with moderate doses of vascoconstrictors will improve diaphragmatic blood flow because the local metabolic activity will help to maintain a selectively lower vascular resistance in the working diaphragm.

Other factors apart from arterial pressure also can compromise diaphragmatic blood flow. At diaphragmatic tensions that are greater than $30 \%$ of peak tension, diaphragmatic flow is obstructed during the contraction phase and flow can only occur during the relaxation phase [43]. This is especially true when the arterial pressure falls, because there is less driving pressure to overcome the tension on the vessels from the contracting muscle [44]. When ventilator frequency increases to the 30 to 40 breaths/minute range, the relaxation time can become sufficiently shortened so that there is not enough time to perfuse the diaphragm properly.

Normally, there is a linear relationship between the PTI of the diaphragm and diaphragmatic oxygen consumption [23] (Figure 3). Because blood flow is linearly related to oxygen consumption, there is also a linear relationship of diaphragmatic blood flow to PTI $[23,29]$. However, when lung injury occurs in sepsis there is progressive hypoxaemia and a fall in arterial oxygen content and oxygen delivery. To compensate, diaphragmatic flow must increase [29] but this can only occur if there are flow reserves, as discussed above. A failure to increase flow will lead to further dysfunction of the ventilatory system and progression of respiratory muscle failure. The limitation in oxygen delivery is especially a problem for the respiratory muscles, because their oxygen need is increased as a result of the increasing demands on the respiratory muscles, and their failure contributes to the hypoxaemia.

A potential consequence of the imbalance between oxygen supply and demand in the respiratory muscles is the development of what is called muscle fatigue, which is characterized by a failure of motor output for a given neural input and, importantly, is relieved only by rest. In other words, once the muscle fails because of fatigue, a period of rest is required before force can once again be generated by the muscle $[20,45,46]$. However, it is not clear how often true muscle fatigue actually occurs, and the ventilatory muscles more often fail because the workload becomes too great for their potential output [47].

It is clear that supporting a septic patient with mechanical ventilation prevents death from ventilator failure, but the use of mechanical ventilation has further therapeutic value. The increased work by ventilatory muscles in patients with respiratory distress requires high oxygen consumption to maintain this activity, and accordingly more blood flow. The needs of the ventilatory muscles thus could potentially consume a large proportion of the available oxygen, especially under conditions of limited blood flow. One study [48] estimated that the respiratory muscles take up as much as $24 \%$ of oxygen consumed by the body in patients with respiratory distress, even though the total ventilation was in the range of $9 \mathrm{l} /$ minute and thus normal. This value was obtained by comparing oxygen consumption before and after the onset of mechanical ventilation. The investigators argued that mechanical ventilation would therefore leave more oxygen to be consumed per minute by the rest of the body, which could be especially important in patients with limited cardiac function. However, the estimate of oxygen consumption by the ventilatory muscles was probably an overestimate because it would have included excess sympathetic activity associated with the respiratory distress.

Subsequent animal studies further tested this issue. These studies showed that mechanically ventilating animals subjected to cardiogenic shock decreased respiratory muscle blood flow, and this was associated with an increase in flow to the brain and kidney $[22,37]$. The same was true in sepsis [36]. It was initially thought that the lower blood flow to vital organs with spontaneous breathing was due to a 'steal phenomenon', in that the vascular resistance in the working ventilator muscles falls and diverts the limited blood flow from vital organs to the ventilatory muscles [22]. In a study with markedly increased ventilator activity caused by oleic acid induced lung injury but normal cardiac function [29], total ventilator muscle flow accounted for $11 \%$ of total cardiac output, and oxygen consumption would be expected to follow a similar proportion of the total. In a model of cardiogenic shock but unobstructed lungs, ventilatory muscles accounted for $20 \%$ of cardiac output [22]. However, when cardiogenic shock was combined with increased elastic load, ventilatory muscle blood flow accounted for only $8 \%$ of the total blood flow, probably because the more forceful muscle contraction began to limit flow and possibly because the muscles were beginning to fail [23]. Similarly, in a dog model of septic shock with a low cardiac output, ventilatory muscles accounted for $9 \%$ of blood flow [36].

Taken together, these studies indicate that unless there is a profound decrease in cardiac output, the energy and flow needs of the diaphragm do not have a major impact on other organs, although limitations in the ventilatory muscles themselves can have major consequences for the whole organism. If vital organs become ischaemic, then it would be expected that their local metabolic factors would dilate their local vascular resistance vessels and help to maintain their proportion of total blood flow, because the relationship of pressure to resistance determines the distribution of flow [39]. The question, then, is why does this not occur? 
One possibility is that a factor related to the increased ventilatory activity results in active vasoconstriction in nonworking muscles. There is indeed evidence for this. As observed in exercise, increased metabolic activity of muscles, including respiratory muscles, leads to increased afferent nerve activity, which increases sympathetic activity and produces generalized vasoconstriction in areas of nonworking muscle $[18,49,50]$. Mechanical ventilation by reducing ventilatory muscle activity turns off this process.

Resting failed respiratory muscles is necessary for force generation to recover. There is also evidence that mechanical ventilation reduces ventilatory muscle injury [51,52]. However, there may be a very important price to pay for this rest. Nerve activity provides an important trophic stimulus to muscles [8,53-58]. As anyone who has suffered a broken limb that required immobilization knows, when a muscle is inactive there is a rapid loss of muscle mass and force. This is also true for ventilatory muscles, and their muscle loss may even be more rapid than occurs in limb muscles. Animals that are maintained under complete ventilatory support for as few as 12 hours have a reduction in the force production of the diaphragm both in vivo and in vitro, and this loss progresses with increasing lengths of ventilator support $[59,60]$. The process is associated with loses of muscle proteins and changes in gene expression [61-63], a shift in muscle fibre type from fast to slow twitch fibres, and an increase in the embryonic form of the acetylcholine receptor. The process is more difficult to demonstrate in human, but it was recently and convincingly demonstrated that humans who are mechanically ventilated and have no spontaneous efforts for 18 to 69 hours exhibit marked atrophy of their diaphragms [64].

In the animal studies the loss of diaphragmatic force is markedly attenuated by allowing the animals to trigger the ventilator [65]. It is therefore likely that efforts will be made to allow at least some triggered activity as soon as possible in ventilated critically ill patients. Strategies that use boluses of narcotics and sedative drugs rather than drips and those that avoid paralyzing agents unless absolutely necessary may help to reduce the loss of ventilator muscle mass in ventilated patients. An important deficiency in research in this area is that, except for some measurements during the first 2 hours of the restoration of spontaneous breathing, there are very few data on the time course and magnitude of recovery of force with resumed spontaneous ventilator efforts [66].

\section{Intrinsic muscle dysfunction}

As sepsis progresses it frequently becomes evident that there is a failure of force generation by muscles and reduced endurance in all muscles. This has immediate consequences in ventilatory muscles (Figure 2a). Muscle dysfunction is especially evident during episodes of fever and even occurs with viral infections [67]. Bosczkowski and coworkers [68] showed in rats that diaphragmatic force generation and endurance decreased 3 days after the injection of Strepto- coccus pneumoniae (Figure 2b). Because these animals survived for 3 days, it is unlikely that shock itself accounts for the diaphragmatic dysfunction. Indeed, arterial pressure and blood gases were not significantly different between infected and control animals. Furthermore, because the animals breathed spontaneously, disuse atrophy also cannot explain the muscle dysfunction. Based on electromyographic studies in mechanically ventilated rats treated with endotoxin, Leon and colleagues [69] concluded that the failure occurred at the neuromuscular junction. In contrast, based on studies that combined phrenic nerve activity and electromyographic studies [20], as well as studies conducted in muscles of animals that were curarized $[70,71]$, Hussain and coworkers [4] concluded that the failure occurs beyond the neuromuscular junction.

The cellular mechanisms for ventilator failure are still the subject of speculation, and I discuss these processes here only briefly, because they are reviewed elsewhere $[3,4,7]$. It is most likely that multiple interacting factors play roles at different time points. For example limitation of substrates such as glycogen does not appear to be a factor early in sepsis [24] but can become important [69] with sustained inadequate perfusion and persistence of the catabolic state in critically ill patients. Depletion of phosphate is associated with muscle failure, and repletion can restore function [72]. However, in the initial phases of sepsis there more often appears to be a failure to use substrates because there is little evidence of substrate depletion.

Muscle dysfunction in sepsis is associated with evidence of oxidative damage $[73,74]$, and scavengers of reactive oxygen species (ROS) reduce the loss of force [70] as well as diaphragmatic dysfunction with mechanical ventilation [75]. Nitric oxide (NO), ROS such as superoxide and hydrogen peroxide are thought to contribute to this process. The role played by $\mathrm{NO}$ in the muscle dysfunction in sepsis is particularly complex. NO is produced by nitric oxide synthases (NOSs), of which there are three isoforms: NOS1 (or neuronal type), NOS2 (or inducible type) and NOS3 (or endothelial type). NOS2 has been found to be induced in the rectus abdominus muscle of septic humans [76], but inhibitors of NOS did not alter contractile responses in these muscles. On the other hand, the addition of the toxic product of $\mathrm{NO}$ and superoxide, peroxynitrite, to normal muscle did decrease function, but this could be a nonspecific toxic effect from an excess of this potent oxidant. In a subsequent study the investigators found that NOS1 was decreased but NOS3 was increased in muscle samples from humans, but overall constitutive NOS activity was reduced. In contrast, studies on rats have tended to find an increase in NOS1 and NOS3 [77]. Importantly, the NOS isoforms have different locations and thus could have local effects. NOS3 is present in blood vessels and plays a role in regulating flow, whereas NOS1 plays a more prominent role in regulation transmission of neural signals. NOS2 is widely distributed and could affect 
multiple pathways. The studies in this area are largely descriptive and thus have limited potential for determining the role played by $\mathrm{NO}$ in the muscle failure of sepsis.

Inhibitors of NOS have been shown to lessen the decrease in diaphragmatic force in endotoxic animals $[77,78]$. However, studies of genetically manipulated mice that are deficient in either NOS2 or NOS1 further confuse the picture, because in these studies the presence of NOS was protective and the absence of either NOS2 or NOS1 led to more muscle injury. The important conclusion from these studies is that simple pharmacological inhibition of NOS is unlikely to be a useful therapeutic approach for respiratory muscle failure. Overall, $\mathrm{NO}$ appears to be adding a regulatory component to underlying physiological processes. Maintenance of normal cell integrity and force generation by a muscle requires the production of energy-rich molecules such as ATP by the mitochondria. Mitochondria fail when there is inadequate oxygen delivery, but they also fail in sepsis with adequate oxygen delivery $[79,80]$, indicating direct suppression by chemical mediators or toxins in what is called 'cytopathic hypoxia' $[81,82]$. This could occur through direct actions of cytokines such as tumour necrosis factor (TNF)- $\alpha$ on mitochondria [83], or indirectly through increased oxidative stress, which could come from increased nitrosylation products due to increased production of $\mathrm{NO}$ and the formation of peroxynitrite $[79,80$, 84-86] as well as increased production of ROS [87] by xanthine oxidase [88], NADPH oxidase [88,89], or prostaglandins $[90,91]$.

Mitochondrial depression as a cause of muscle failure might be expected to be associated with depletion of intracellular ATP. This has been observed in skeletal muscles of rats in some studies, but to a smaller extent than seen in the liver [80], and is not observed in all studies [92]. However, the concentration of ATP is not a good guide to the role of bioenergetic failure because even when there is a marked increase in consumption of ATP, as occurs during normal exercise, the concentration of ATP usually stays constant. This indicates that the real issue is production relative to need, which is experimentally very difficult to assess. The more useful measure is probably maximal ATP production, which has been shown to be reduced in sepsis [92], indicating that the failure of production to match needs is a likely factor.

Based on the evidence in animals that ROS scavengers can reduce diaphragmatic dysfunction is sepsis $[70,71]$ as well as diaphragmatic dysfunction in mechanically ventilated patients [75], it has been proposed that the use of oxygen radical scavengers might be of potential therapeutic value for the treatment of ventilatory muscle dysfunction in humans. The problem with this reasoning is that it has become apparent that the redox state of the cell plays an important role in regulating intracellular events $[93,94]$ and ROS are particularly important for cytokine signalling and growth factors. The redox-sensitive signalling of cytokines occurs through regulation of the activity of nuclear factor $-\kappa B(N F-\kappa B)$ $[95,96]$ and alteration in redox state has positive and negative effects on NF- $\kappa B$ activity. It has also become apparent that it is not simply oxygen radicals that are important but the redox state of all ROS, of which oxygen radicals are only a tiny fraction $[97,98]$. Furthermore, the redox environment of the cell is highly compartmentalized, with major differences between the cytoplasm and nucleus, as well as probably in the cytoplasm itself [99]. It is possible that positive results with ROS scavengers on diaphragmatic function that were observed in short-term animal experiments $[70,71,100]$ were related to the modification of these signalling pathways, but it is difficult to predict what would happen when these substances are used to alter the intracellular milieu in the complexity of the critically ill patient. Therapeutic approaches should try to 'regulate' and not 'obliterate'!

As time progresses, a substantial proportion of the decrease in muscle force production in sepsis is related to a decrease in muscle mass, which can occur in less than 48 hours [92]. Sepsis is associated with abnormal protein metabolism, which is part of an overall strategy that redirects metabolic pathways to factors that are required to deal with the inflammatory response [101]. Because skeletal muscle is the largest repository of protein in the body, it is not surprising that proteins from muscles, including ventilatory muscles, are broken down to provide amino acids for molecules needed in the inflammatory response. A major cytokine in the sepsis cascade is TNF- $\alpha$. This cytokine produces an immediate decrease in contractile function that is not due to altered calcium transits, indicating direct alteration in contractile proteins [102]. It is well recognized that TNF- $\alpha$ causes muscle wasting in inflammatory processes and cancer, and was actually originally called 'cachexin' [103]. TNF- $\alpha$ increases breakdown of myosin heavy chains in muscle cells in culture, which is evident as atrophy in muscles of intact animals [104]. Intracellular signalling for TNF- $\alpha$ occurs primarily through NF- $\mathrm{B}$ [105]. Because NF- $\kappa \mathrm{B}$ is also a key signalling molecule for IL-1 and endotoxin [106], it would not be surprising that the muscle breakdown with these substances $[69,71,107,108]$ also occurs through NF- $\kappa B$. Activation of NF- $\kappa B$ by TNF- $\alpha$ increases muscle-specific ring-finger protein 1 (MuRF1), which is known to cause muscle wasting [109]. TNF- $\alpha$ also produces insulin resistance and decreases insulin-like growth factor-1. The consequence of this is decreased activity of the threonine serine kinase Akt, which is a key switch in the cell that controls paths leading to either protein production or breakdown, because Akt is activated by insulin and insulin-like growth factor-1. Akt activates the mammalian target of rapamycin, which is a key regulator of intracellular protein production. It also phosphorylates the forkhead box O (FOXO) transcription factor, which prevents its migration to the nucleus. When allowed to go to the nucleus, FOXO increases the transcription of atrophic genes including Atrogen-1 and Murf-1 [109-111]. 
TNF- $\alpha$ also acts through NF- $\mathrm{KB}$ to inhibit production of $M y o D$ mRNA, a key regulator of expression of the skeletal muscle differentiation programme; this could impair the repair and restoration of muscle proteins when degradation has been accelerated. Inhibition of NF-KB prevents protein breakdown in isolated myotubes [112] and reduces atrophy after unloading of muscle [109]. Based on these types of studies, it has been suggested that a therapeutic option is to inhibit $\mathrm{NF}-\mathrm{KB}$ to prevent muscle wasting in sepsis and preserve ventilatory muscle function. I predict that this is unlikely to be successful in humans because of the broad role that NF-KB plays in the overall inflammatory response, including the production of many molecules that help to turn off the inflammatory response.

There is an important potential interaction between ventilatorassociated muscle loss and sepsis. As already discussed, decreasing neural activity results in cellular alterations that lead to protein loss and changes in the phenotype of the muscles, as well as increased expression of proteins involved in the skeletal muscle differentiation programme, including MyoD and Myogenin $[55,57,58]$. These are potentially important for the repair process. TNF- $\alpha$, on the other hand, inhibits production of MyoD through an NF-KB dependent pathway [113]. This could amplify ventilator-associated ventilatory muscle dysfunction.

\section{Heart-lung interactions}

Changes in the ventilatory pattern with sepsis have implications for heart-lung interactions [40]. Because dynamic compliance is decreased in sepsis, inspiratory effort must be greater for the same tidal volume and consequently pleural pressure swings for each breath must increase. The inspiratory fall in pleural pressure lowers the environment of the heart relative to the rest of the body, and consequently increases the gradient for venous return during the inspiratory effort (Figure 4a). Because the normal gradient for the return of blood to the right heart is only in the range of 3 to $6 \mathrm{mmHg}$ [41,114], increased inspiratory swings can have a substantial effect on the flow of blood back to the heart. Of importance, there is a limit to this effect. When the pressure inside veins falls to below the surrounding pressure, soft walled veins collapse and the gradient for the return of blood is then from the upstream pressure to the site of the collapse. This is known as a vascular waterfall [115]. In a spontaneously breathing person collapse of veins occurs when venous pressure falls below atmospheric pressure but in a ventilated patient collapse occurs when venous pressure falls below the pleural pressure, which is above atmospheric pressure [116].

Because of the vascular waterfall, the effect of inspiration on venous return is very dependent upon the initial right atrial pressure. In a healthy person, right atrial pressure is either below or close to the collapse pressure so that inspiratory increases in right heart filling are small. However, in a patient who has been excessively volume resuscitated, the inspira- tory increase in venous return can be substantially increased (Figure 4b). Furthermore, there is an important series effect on the right and left heart. The increase in right heart filling with inspiration must be passed to the left heart. If left heart function is decreased, especially its diastolic function, then swings in left atrial pressure can be considerably exaggerated. When this is associated with increased capillary permeability, as typically occurs in sepsis, these swings in left atrial pressure will further contribute to pulmonary oedema. This will further decrease dynamic pulmonary compliance, which will result in greater negative swings in pleural pressure and add another positive feedback loop. Of importance, the mean cardiac output itself will not give an indication of the process; the process can only be identified by looking at the magnitude of the inspiratory swings on the central venous tracing or pulmonary artery occlusion pressure if it is being measured [117] or by stroke volume measurements by Doppler.

The increased fall in pleural pressure also has an effect on left ventricular ejection, because it means that the left heart must start its contraction from a more negative value and the left heart thus effectively has a greater afterload $[118,119]$. If the left heart starts with an elevated diastolic filling pressure and is thus on the steeper portion of its diastolic filling curve, then the increase in venous return with inspiration will result in large increases in left ventricular diastolic pressures and consequently a large increase in pulmonary capillary pressure, which will also lead to more pulmonary leak.

Another factor that can contribute to swings in cardiac filling pressures during the ventilatory cycle is active contraction of abdominal muscles during expiration. Normally, expiration is passive, but patients with lung injury, intra-abdominal sepsis, or altered sensorium often have forced expiratory efforts. This action increases abdominal pressure during expiration and can result in increased venous return during these contractions and further exaggerate the oscillatory pattern in cardiac filling pressures.

The inspiratory increase in venous return described above can only occur if the heart is functioning on the ascending part of the cardiac function curve. If the heart is functioning on the flat part of the curve, venous return cannot increase nor does the cardiac filling pressure increase relative to atmosphere (Figure 4c). However, the filling pressure across the wall, that is the transmural pressure, can increase substantially and this can affect coronary flow and the interaction of the left and right ventricles.

As ventilatory muscle function deteriorates in sepsis the inspiratory effects on venous return will decrease, but when the patient requires mechanical ventilation a new set of problems emerges. Now with each breath there is a decrease in venous return and an increase during the expiratory phase (Figure 4d). If the breaths are triggered, the effects from the 
(a)

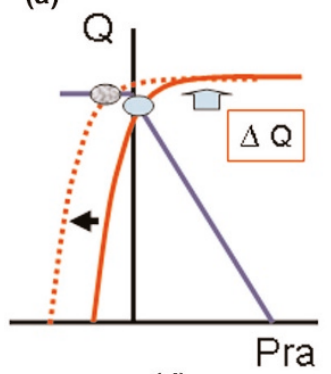

(d) (b)

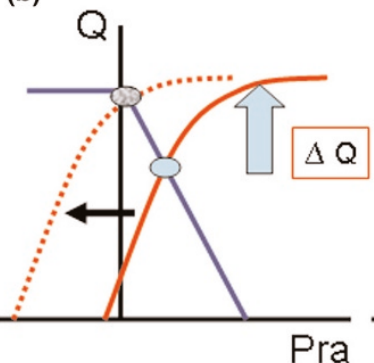

(c)

(e)

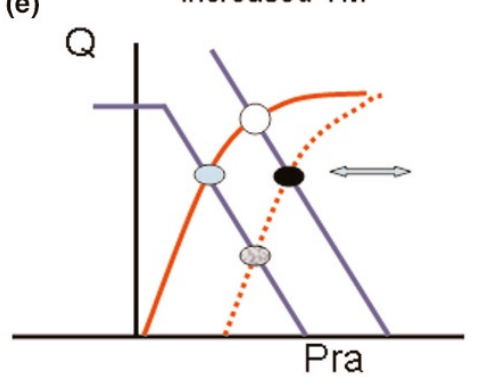

Ventilatory effects on the relationship between cardiac function and venous return at different potential stages in sepsis. Cardiac function is indicated by curved lines, and venous return by straight lines. (a) With spontaneous breaths the pressure around the heart falls relative to atmospheric pressure, which is represented by a leftward shift of the cardiac function curve. Under basal conditions the cardiac function curve intersects the venous return curve near the plateau of the venous return curve, so that the leftward shift produces only a small or no increase in right heart filling with inspiration. (b) If the right atrial pressure starts from a higher value and the fall in pleural pressure is increased because of changing pulmonary mechanics, then the inspiratory increase in right heart stroke volume is increased. (c) If the heart is functioning on the plateau of the cardiac function curve, there is no increase in right heart filling with inspiration. However, there is an increase in the transmural pressure (pressure across the wall) of the heart. (d) When a patient is ventilated with positive pressure, inspiration moves the cardiac function curve to the right. There is thus an inspiratory fall in right ventricular stroke volume and a rise in venous pressure, which can affect upstream organs such as liver and kidney. (e) The reduction in cardiac output with continuous positive pressure can be reversed by giving volume, which shifts the venous return curve to the right (dark circle). However, when positive pressure is removed this will result increased cardiac filling, and if the left ventricle does not handle the increased flow (open circle) pulmonary oedema may result. Pra, right atrial pressure; TM, transmural pressure.

inspiratory efforts discussed above also persist. If there is also active abdominal muscle contraction during expiration, the expiratory increase in venous return will exaggerate the swings in filling pressures (Figure $4 \mathrm{e}$ ).

A further problem arises when increasing amounts of PEEP are required. This increases the proportion of the lung in West zone II, especially during the inspiratory phase. In regions of the lung where this occurs, the downstream pressure for flow is the pressure in the alveolus, and the increase in this pressure can result in a large reduction in flow through the lungs during this phase of the ventilator cycle $[120,121]$. This will also contribute to an oscillatory pattern in cardiac filling pressures and flow, and could contribute to capillary leak. On the other hand, the rise in pleural pressure with PEEP inhibits venous return and can potentially help 'decompress' over-filled ventricles. When cardiac output decreases because of an increase in pleural pressure, there is reflex constriction of capacitance vessels as well as fluid retention by the kidney that increases venous pressures and helps restore venous return and cardiac output [122]. However, when the patient recovers and mechanical ventilation is withdrawn, removal of the positive pressure allows increased venous return and an increase in cardiac filling pressures. If ventricular function is adequate then the increase in return volume will be successfully handled, but if ventricular function is inadequate this can marked increase cardiac filling pressures and lead to pulmonary oedema and ventilatory failure [123]. To avoid this problem it is important that mechanical support be progressively decreased and excess vascular volume removed by diuresis before extubation. In patients who are very fragile, it may sometimes be necessary before extubation to diurese them to a point where they are pre-renal, because otherwise they may have sufficient volume for adequate cardiac output on the ventilator but too much for off the ventilator.

\section{Conclusion}

Pulmonary abnormalities are common in septic patients, and if ventilation is not supported ventilatory failure is potentially an early cause of death. It is important to consider how the general septic state interferes and limits ventilatory muscle function, but also how abnormal ventilatory muscle function interacts with other body systems, especially the 
cardiovascular system. In patients who are ill for prolonged periods of time, it important to consider the progressive weakening of the ventilatory pump, which then must face increased loads because of resolving lung injury. Proper management of these patients requires a good understanding of all of the pathophysiological factors involved.

\section{Competing interests}

The author declares that they have no competing interests.

\section{References}

1. Montgomery AB, Stager MA, Carrico CJ, Hudson LD: Causes of mortality in patients with the adult respiratory distress syndrome. Am Rev Respir Dis 1985, 132:485-489.

2. Hussain SNA, Magder S: Respiratory muscle function in shock and infection. Semin Respir Med 1991, 12:287-297.

3. Lanone S, Taille C, Boczkowski J, Aubier M: Diaphragmatic fatigue during sepsis and septic shock. Intensive Care Med 2005, 31:1611-1617.

4. Hussain SN: Respiratory muscle dysfunction in sepsis. Mol Cell Biochem. 1998, 179:125-134.

5. Hussain SN: Regulation of ventilatory muscle blood flow. J Appl Physiol 1996, 81:1455-1468.

6. Rochester DF, Esau SA: Critical illness, infection and the respiratory muscles. Am Rev Respir Dis 1988, 138:258-259.

7. Laghi F, Tobin MJ: Disorders of the respiratory muscles. $A m \mathrm{~J}$ Respir Crit Care Med 2003, 168:10-48.

8. Gayan-Ramirez G, Decramer M: Effects of mechanical ventilation on diaphragm function and biology. Eur Respir J 2002, 20: 1579-1586.

9. Bone RC, Fisher CJ, Clemmer TP, Slotman GJ, Metz CA, Balk RA: Sepsis syndrome: a valid clinical entity. Crit Care Med 1989, 17:389-393.

10. Amoateng-Adjepong $Y$, Jacob BK, Ahmad M, Manthous CA: The effect of sepsis on breathing pattern and weaning outcomes in patients recovering from respiratory failure. Chest 1997, 112:472-477

11. Law WR, Donahue PE, Ferguson JL: Dramatic changes in blood gases that are unrelated to arterial $\mathrm{pH}$ or cerebral oxygen delivery during endotoxin shock in conscious rats. Circ Shock 1985, 15:49-59.

12. Severinghaus JW: Endotoxin hyperventilation mechanisms. Crit Care Med 1998, 26:1481-1482.

13. Zhang JF, Yu J, Fletcher EC: Stimulation of breathing by activation of pulmonary peripheral afferents in rabbits. J Appl Physiol 1998, 85:1485-1492.

14. Magder S: Effects of respiratory muscle afferent on the breathing and the afferent hypothesis. In Respiratory-Circulatory Interactions in Health and Disease, 2nd ed. Edited by Scharf SM, Pinsky MR, Magder S. New York, NY: Marcel Dekker, Inc.; 2001:405-425.

15. Teitelbaum JS, Magder SA, Roussos C, Hussain SNA: Effects of diaphragmatic ischemia on the inspiratory motor drive. J Appl Physiol 1992, 72:447-454.

16. Hussain S, Magder S, Chatillon A, Roussos Ch: Chemical activation of thin-fibre phrenic afferents: 1) the respiratory responses. J App/ Physiol 1990, 69:1002-1011.

17. Hussain SNA, Magder SA, Chatillon A, Roussos C: Chemical activation of thin-fiber phrenic afferents: respiratory responses. J Appl Physiol 1990, 69:1002-1011.

18. Hussain S, Chatillon A, Comtois A, Roussos Ch, Magder S: The chemical activation of thin-fiber phrenic afferents:cardiovascular responses. J Appl Physiol 1991, 70:77-86.

19. Hussain SNA, Simkus G, Roussos C: Ventilatory muscle fatigue: a cause of hypercapnic respiratory failure during endotoxic shock in dogs. J Appl Physiol 1985, 58:2033-2040.

20. Hussain SNA, Simkus G, Roussos C: Respiratory muscle fatigue: a cause of ventilatory failure in septic shock. $J$ Appl Physiol 1985, 58:2033-2040.

21. Aubier M, Trippenbach $T$, Roussos $C$ : Respiratory muscle fatigue during cardiogenic shock. J Appl Physiol 1981, 51:499-508.

22. Viires N, Sillye G, Aubier M, Rassidakis A, Roussos C: Regional blood flow distribution in dog during induced hypotension and low cardiac output. Spontaneous breathing versus artificial ventilation. J Clin Invest 1983, 72:935-947.

23. Magder SA, Lockhat D, Luo BJ, Roussos Ch: Respiratory muscle and organ blood flow with inspiratory elastic loading and shock. J Appl Physiol 1985, 58:1148-1156.

24. Hussain SNA, Graham R, Rutledge F, Roussos Ch: Respiratory muscle energetics during endotoxic shock in dogs. J Appl Physiol 1986, 60:486-493.

25. Roussos C, Zakynthinos S: Respiratory muscle energetics. In The Thorax, 2nd edn. Edited by Roussos C. New York: Marcel Dekker Inc; 1995:681-749.

26. Buchler B, Magder S, Roussos C: Effects of contraction frequency and duty cycle on diaphragmatic blood flow. J Appl Physiol 1985, 58:265-273.

27. Buchler B, Magder SA, Roussos Ch: Effects of contraction frequency and duty cycle on diaphragmatic blood flow. J Appl Physiol 1985, 58:265-273.

28. Buchler B, Magder SA, Katsardis H, Jammes $\mathrm{Y}$, Roussos Ch: Effects of pleural pressure and abdominal pressure on diaphragmatic blood flow. J Appl Physiol 1985, 58:691-697.

29. Magder SA, Erian RF, Roussos Ch: Respiratory muscle blood flow in oleic acid-induced pulmonary edema. J Appl Physiol 1986, 60:1849-1856.

30. Sharp JT, Griffith GT, Bunnell IL, Greene DG: Ventilatory mechanics in pulmonary edema in man. J Clin Invest 1958, 37: 111-117.

31. Slutsky AS, Scharf SM, Brown R, Ingram RH Jr: The effect of oleic acid-induced pulmonary edema on pulmonary and chest wall mechanics in dogs. Am Rev Respir Dis 1980, 121:91-96.

32. Gattinoni L, Caironi P, Pelosi P, Goodman LR: What has computed tomography taught us about the acute respiratory distress syndrome? Am J Respir Crit Care Med 2001, 164: 1701-1711.

33. Gattinoni L, Pelosi P, Suter PM, Pedoto A, Vercesi P, Lissoni A: Acute respiratory distress syndrome caused by pulmonary and extrapulmonary disease. Different syndromes? $A m$ J Respir Crit Care Med 1998, 158:3-11.

34. Kallet RH, Alonso JA, Pittet JF, Matthay MA: Prognostic value of the pulmonary dead-space fraction during the first 6 days of acute respiratory distress syndrome. Respir.Care 2004, 49: 1008-1014.

35. Freedman S, Campbell EJ: The ability of normal subjects to tolerate added inspiratory loads. Respir Physiol 1970, 10:213235.

36. Hussain SNA, Roussos C: Distribution of respiratory muscle and organ blood flow during endotoxic shock in dogs. J Appl Physiol 1985, 59:1802-1808.

37. Magder SA, Lockhat D, Luo BJ, Ducas D, Roussos Ch: Blood flow distribution in hypotensive (tamponade) and inspiratory elastic loading [abstract]. Fed Proc 1983, 42:1855.

38. Hussain S, Roussos Ch, Magder SA: Autoregulation of diaphragmatic blood flow in dogs. J Appl Physiol 1988, 64: 329-336.

39. Magder SA: Pressure-flow relations of diaphragm and vital organs with nitroprusside-induced vasodilation. J Appl Physiol 1986, 61:409-416.

40. Magder S: Heart-lung interactions in sepsis. In Respiratory-Circulatory Interactions in Health and Disease, 2nd ed. Edited by Scharf SM, Pinsky M, Magder S. New York, NY: Marcel Dekker Inc.; 2001:739-762

41. Magder S, Scharf SM: Venous return. In Respiratory-Circulatory Interactions in Health and Disease, 2nd ed. Edited by Scharf SM, Pinsky MR, Magder SA. New York, NY: Marcel Dekker, Inc.; 2001:93-112.

42. Hussain SNA, Rutledge F, Graham R, Magder S, Roussos C: Effects of norepinephrine and fluid administration on diaphragmatic $\mathrm{O}_{2}$ consumption in septic shock. J Appl Physiol 1987, 62:1368-1376.

43. Hussain SNA, Magder S: Diaphragmatic intramuscular pressure in relation to tension, shortening and blood flow. $J \mathrm{Appl}$ Physiol 1991, 71:159-167.

44. Hussain SNA, Roussos Ch, Magder S: The selective effects of tension, duty cycle and arterial pressure on diaphragmatic blood flow. J Appl Physiol 1989, 66:968-976.

45. Cohen CA, Zagelbaum G, Gross D, Roussos C, Macklem PT: Clinical manifestations of inspiratory muscle fatigue. $A m$ J Med 1982, 73:308-316. 
46. Aubier M, Trippenbach $T$, Roussos $C$ : Respiratory muscle fatigue during cardiogenic shock. J App/ Physiol 1981, 51:494-498.

47. Sassoon CS, Gruer SE, Sieck GC: Temporal relationships of ventilatory failure, pump failure, and diaphragm fatigue. $J \mathrm{Appl}$ Physiol 1996, 81:238-245.

48. Field S, Kelly SM, Macklem PT: The oxygen cost of breathing in patients with cardiorespiratory disease. Am Rev Respir Dis 1982, 126:9-13

49. Crayton SC, Mitchell JH, Payne FCl: Reflex cardiovascular response during injection of capsaicin into skeletal muscle. Am J Physiol 1981, 240:H315-H319.

50. Kaufman MP, Iwamoto GA, Longhurst JC, Mitchell JH: Effects of capsaicin and bradykinin on afferent fibers with endings in skeletal muscle. Circ Res 1982, 50:133-139.

51. Ebihara S, Hussain SN, Danialou G, Cho WK, Gottfried SB, Petrof $B J$ : Mechanical ventilation protects against diaphragm injury in sepsis: interaction of oxidative and mechanical stresses. Am J Respir Crit Care Med 2002, 165:221-228.

52. Laghi F: Curing the septic diaphragm with the ventilator. Am J Respir.Crit Care Med 2002, 165:145-146.

53. Gundersen K, Sanes JR, Merlie JP: Neural regulation of muscle acetylcholine receptor epsilon- and alpha-subunit gene promoters in transgenic mice. J Cell Biol 1993, 123:1535-1544.

54. Ekmark M, Rana ZA, Stewart G, Hardie DG, Gundersen K: Dephosphorylation of MyoD is linking nerve-evoked activity to fast myosin heavy chain expression in rodent adult skeletal muscle. J Physiol 2007, 584:637-650.

55. Schiaffino S, Sandri M, Murgia M: Activity-dependent signaling pathways controlling muscle diversity and plasticity. Physio/ogy (Bethesda) 2007, 22:269-278.

56. Bassel-Duby R, Olson EN: Signaling pathways in skeletal muscle remodeling. Annu Rev Biochem 2006, 75:19-37.

57. Buonanno A, Apone L, Morasso MI, Beers R, Brenner HR, Eftimie R: The MyoD family of myogenic factors is regulated by electrical activity: isolation and characterization of a mouse Myf-5 cDNA. Nucleic Acids Res 1992, 20:539-544.

58. Eftimie R, Brenner HR, Buonanno A: Myogenin and MyoD join a family of skeletal muscle genes regulated by electrical activity. Proc Natl Acad Sci USA 1991, 88:1349-1353.

59. Sassoon CS, Caiozzo VJ, Manka A, Sieck GC: Altered diaphragm contractile properties with controlled mechanical ventilation. J Appl Physiol 2002, 92:2585-2595.

60. Powers SK, Shanely RA, Coombes JS, Koesterer TJ, McKenzie M, Van Gammeren D, Cicale M, Dodd SL: Mechanical ventilation results in progressive contractile dysfunction in the diaphragm. J Appl Physiol 2002, 92:1851-1858.

61. Shanely RA, Van Gammeren D, Deruisseau KC, Zergeroglu AM, McKenzie MJ, Yarasheski KE, Powers SK: Mechanical ventilation depresses protein synthesis in the rat diaphragm. Am J Respir Crit Care Med 2004, 170:994-999.

62. Racz GZ, Gayan-Ramirez G, Testelmans D, Cadot P, de Paepe K, Zador $E$, Wuytack $F$, Decramer $M$ : Early changes in rat diaphragm biology with mechanical ventilation. $A m$ J Respir Crit Care Med 2003, 168:297-304

63. Deruisseau KC, Shanely RA, Akunuri N, Hamilton MT, Van Gammeren D, Zergeroglu AM, McKenzie M, Powers SK: Diaphragm unloading via controlled mechanical ventilation alters the gene expression profile. Am J Respir Crit Care Med 2005, 172: 1267-1275.

64. Levine S, Nguyen T, Taylor N, Friscia ME, Budak MT, Rothenberg $P$, Zhu J, Sachdeva R, Sonnad S, Kaiser LR, Rubinstein NA Powers SK, Shrager JB: Rapid disuse atrophy of diaphragm fibers in mechanically ventilated humans. $N$ Engl J Med 2008, 358:1327-1335.

65. Sassoon CS, Zhu E, Caiozzo VJ: Assist-control mechanical ventilation attenuates ventilator-induced diaphragmatic dysfunction. Am J Respir.Crit Care Med 2004, 170:626-632.

66. Van Gammeren D, Falk DJ, Deruisseau KC, Sellman JE, Decramer M, Powers SK: Reloading the diaphragm following mechanical ventilation does not promote injury. Chest 2005, 127:22042210.

67. Friman G: Effect of acute infectious disease on isometric muscle strength. Scand J Clin Lab Invest 1977, 37:303-308.

68. Boczkowski J, Dureuil B, Branger C, Pavlovic D, Murciano D, Pariente R, Aubier M: Effects of sepsis on diaphragmatic function in rats. Am Rev Resp Dis 1988, 138:260-265.

69. Leon A, Boczkowski J, Dureuil B, Desmonts J-M, Aubier M:
Effects of endotoxic shock on diaphragmatic function in mechanically ventilated rats. J Appl Physiol 1992, 72:14661472.

70. Shindoh C, DiMarco A, Thomas A, Manubay P, Supinski G: Effect of PEG-superoxide dismutase on the diaphragmatic response to endotoxin. Am Rev Respir Dis 1992, 145:1350-1354.

71. Supinski G, Nethery D, DiMarco C: Effect of free radical scavengers on endotoxin-induced respiratory muscle dysfunction. Am Rev Respir Dis 1993, 148:1318-1324.

72. Aubier M, Murciano D, Lecocguic $Y$, Viires N, Jacquens $Y$, Squara P, Pariente R: Effect of hypophosphatemia on diaphragmatic contractility in patients with acute respiratory failure. $N$ Engl $J$ Med 1985, 313:420-424.

73. Callahan LA, Nethery D, Stofan D, DiMarco A, Supinski G: Free radical-induced contractile protein dysfunction in endotoxininduced sepsis. Am J Respir.Cell Mol Biol 2001, 24:210-217.

74. Barreiro E, Comtois AS, Gea J, Laubach VE, Hussain SN: Protein tyrosine nitration in the ventilatory muscles: role of nitric oxide synthases. Am J Respir Cell Mol Biol 2002, 26:438-446.

75. Betters JL, Criswell DS, Shanely RA, Van Gammeren D, Falk D, Deruisseau KC, Deering M, Yimlamai T, Powers SK: Trolox attenuates mechanical ventilation-induced diaphragmatic dysfunction and proteolysis. Am J Respir Crit Care Med 2004, 170: 1179-1184.

76. Lanone S, Mebazaa A, Heymes C, Henin D, Poderoso JJ, Panis $Y$, Zedda C, Billiar T, Payen D, Aubier M, Boczkowski J: Muscular contractile failure in septic patients: role of the inducible nitric oxide synthase pathway. Am J Respir Crit Care Med 2000, 162: 2308-2315.

77. El-Dwairi Q, Comtois A, Guo Y, Hussain SNA: Endotoxininduced skeletal muscle contractile dysfunction: contribution of nitric oxide synthases. Am J Physiol 1998, 274:C770-C779.

78. Boczkowski J, Lanone S, Ungureanu-Longrois D, Danialou G, Fournier T, Aubier M: Induction of diaphragmatic nitric oxide synthase after endotoxin administration in rats: role on diaphragmatic contractile dysfunction. J Clin.Invest 1996, 98: 1550-1559.

79. Brealey D, Brand M, Hargreaves I, Heales S, Land J, Smolenski R, Davies NA, Cooper CE, Singer M: Association between mitochondrial dysfunction and severity and outcome of septic shock. Lan 2002, 360:219-223.

80. Brealey D, Karyampudi S, Jacques TS, Novelli M, Stidwill R, Taylor $\mathrm{V}$, Smolenski RT, Singer M: Mitochondrial dysfunction in a longterm rodent model of sepsis and organ failure. Am J Physiol Regul Integr Comp Physiol 2004, 286:R491-R497.

81. Singer $M$ : Mitochondrial function in sepsis: acute phase versus multiple organ failure. Crit Care Med 2007, 35:S441S448.

82. Schwartz DR, Malhotra A, Fink MP: Cytopathic hypoxia in sepsis: an overview. Sepsis 1998, 2:279-289.

83. Corda S, Laplace C, Vicaut E, Duranteau J: Rapid reactive oxygen species production by mitochondria in endothelial cells exposed to tumor necrosis factor-alpha is mediated by ceramide. Am J Respir Cell Mol Biol 2001, 24:762-768.

84. Frost RA, Lang $\mathrm{CH}$ : Protein kinase B/Akt: a nexus of growth factor and cytokine signaling in determining muscle mass. Appl Physiol 2007, 103:378-387.

85. Cleeter MWJ, Cooper JM, Darley-Usmar VM, Moncada S, Schapira AHV: Reversible inhibition of cytochrome c oxidase, the terminal enzyme of the mitochondrial respiratory chain, by nitric oxide. FEBS Lett 1994, 345:50-54.

86. Boczkowski J, Lisdero CL, Lanone S, Samb A, Carreras MC, Boveris A, Aubier M, Poderoso JJ: Endogenous peroxynitrite mediates mitochondrial dysfunction in rat diaphragm during endotoxemia. FASEB J 1999, 13:1637-1646.

87. Callahan LA, Stofan DA, Szweda LI, Nethery DE, Supinski GS: Free radicals alter maximal diaphragmatic mitochondrial oxygen consumption in endotoxin-induced sepsis. Free Radic Biol Med 2001, 30:129-138.

88. Brandes RP, Koddenberg G, Gwinner W, Kim D-Y, Kruse H-J, Busse R, Mugge A: Role of increased production of superoxide anions by $\mathrm{NAD}(\mathrm{P}) \mathrm{H}$ oxidase and xanthine oxidase in prolonged endotoxemia. Hypertension 1999, 33:1243-1249.

89. Javeshghani D, Magder SA, Barreiro E, Quinn MT, Hussain SNA: Molecular characterization of a superoxide-generating $\mathrm{NAD}(\mathrm{P}) \mathrm{H}$ oxidase in the ventilatory muscles. $\mathrm{Am} J$ Resp Crit Care Med 2002, 165:412-418. 
90. Ruff RL, Secrist D: Inhibitors of prostaglandin synthesis or cathepsin B prevent muscle wasting due to sepsis in the rat. $J$ Clin Invest 1984, 73:1483-1486.

91. Turinsky J, Loegering DJ: Prostaglandin E2 and muscle protein turnover in Pseudomonas aeruginosa sepsis. Biochim Biophys Acta 1985, 840:137-140.

92. Giannesini B, Izquierdo M, Dalmasso C, Le Fur Y, Cozzone PJ, Verleye M, Le Guern ME, Gillardin JM, Bendahan D: Endotoxemia does not limit energy supply in exercising rat skeletal muscle. Muscle Nerve 2008, 37:496-504.

93. Finkel T: Oxygen radicals and signaling. Curr Opin Cell Biol 1998, 10:248-253.

94. Magder S: Review: Reactive oxygen species: toxic molecules or spark of life? Crit Care 2006, 10:208.

95. Gloire G, Legrand-Poels S, Piette J: NF-kappaB activation by reactive oxygen species: fifteen years later. Biochem Pharma$\mathrm{col}$ 2006, 72:1493-1505

96. Janssen-Heininger YMW, Poynter ME, Baeuerle PA: Recent advances torwards understanding redox mechanisms in the activation of nuclear factor $\mathrm{kb}$. Free Radical Biol Med 2000, 28: 1317-1327.

97. Jones DP: Radical-free biology of oxidative stress. $A m$ J Physiol Cell Physiol 2008, 295:849-868.

98. Kemp M, Go YM, Jones DP: Nonequilibrium thermodynamics of thiol/disulfide redox systems: a perspective on redox systems biology. Free Radic.Biol Med 2008, 44:921-937.

99. Go YM, Jones DP: Redox compartmentalization in eukaryotic cells. Biochim.Biophys.Acta 2008, 1780:1273-1290.

100. Shindoh C, DiMarco A, Thomas A, Manubay P, Supinski G: Effect of $\mathrm{N}$-acetylcysteine on diaphragm fatigue. J Appl Physiol 1990, 68:2107-2113.

101. Nathan C: Points of control in inflammation. Nature 2002, 420 : 846-852.

102. Reid MB, Lannergren J, Westerblad H: Respiratory and limb muscle weakness induced by tumor necrosis factor-alpha: involvement of muscle myofilaments. Am J Respir Crit Care Med 2002, 166:479-484.

103. Beutler B, Cerami A: Cachectin and tumor necrosis factor as two sides of the same biological coin. Nature 1986, 320:584588.

104. Zamir O, Hasselgren PO, Kunkel SL, Frederick J, Higashiguchi T, Fischer JE: Evidence that tumor necrosis factor participates in the regulation of muscle proteolysis during sepsis. Arch Surg 1992, 127:170-174.

105. Kempe S, Kestler H, Lasar A, Wirth T: NF-kappaB controls the global pro-inflammatory response in endothelial cells: evidence for the regulation of a pro-atherogenic program. Nucleic Acids Res 2005, 33:5308-5319.

106. Magder S, Neculcea J, Neculcea V, Sladek R: Lipopolysaccharide and TNF-alpha produce very similar changes in gene expression in human endothelial cells. J Vasc Res 2006, 43: 447-461.

107. Zamir O, Hasselgren PO, O'Brien W, Thompson RC, Fischer JE: Muscle protein breakdown during endotoxemia in rats and after treatment with interleukin-1 receptor antagonist (IL-1ra). Ann Surg 1992, 216:381-385.

108. Shindoh C, DiMarco A, Nethery D, Supinski G: Effect of PEGsuperoxide dismutase on the diaphragmatic response to endotoxin. Am Rev Respir Dis 1992, 145:1350-1354.

109. Sandri M: Signaling in muscle atrophy and hypertrophy. Physiology (Bethesda) 2008, 23:160-170.

110. Sandri M, Sandri C, Gilbert A, Skurk C, Calabria E, Picard A, Walsh K, Schiaffino S, Lecker SH, Goldberg AL: Foxo transcription factors induce the atrophy-related ubiquitin ligase atrogin-1 and cause skeletal muscle atrophy. Cell 2004, 117: 399-412.

111. Mammucari C, Schiaffino S, Sandri M: Downstream of Akt: FoxO3 and mTOR in the regulation of autophagy in skeletal muscle. Autophagy. 2008, 4:524-526.

112. Li YP, Reid MB: NF-kappaB mediates the protein loss induced by TNF-alpha in differentiated skeletal muscle myotubes. $A m$ J Physiol Regul Integr Comp Physiol 2000, 279:R1165-R1170.

113. Guttridge DC, Mayo MW, Madrid LV, Wang CY, Baldwin AS Jr: NF-kappaB-induced loss of MyoD messenger RNA: possible role in muscle decay and cachexia. Science 2000, 289:23632366.

114. Guyton AC, Lindsey AW, Kaufman BN: Effect of mean circula- tory filling pressure and other peripheral circulatory factors on cardiac output. Am J Physiol 1955, 180:463-468.

115. Permutt S, Riley S: Hemodynamics of collapsible vessels with tone: the vascular waterfall. J Appl Physiol 1963, 18:924-932.

116. Fessler HE, Brower RG, Wise RA, Permutt S: Effects of positive end-expiratory pressure on the canine venous return curve. Am Rev Respir Dis 1992, 146:4-10.

117. Bellemare P, Goldberg P, Magder S: Do inspiratory changes in pulmonary artery occlusion pressure reflect changes in pleural pressure? Am J Resp Crit Care Med 2004, 169:A343.

118. Magder SA, Lichtenstein S, Adelman AG: Effects of negative pleural pressure on left ventricular hemodynamics. Am J Cardiol 1983, 52:588-593.

119. McGregor M: Current concepts: pulsus paradoxus. $N$ Engl J Med 1979, 301:480-482.

120. Vieillard-Baron A, Loubieres Y, Schmitt JM, Page B, Dubourg O, Jardin F: Cyclic changes in right ventricular output impedance during mechanical ventilation. J Appl Physiol 1999, 87:16441650.

121. Jardin F, Vieillard-Baron A: Right ventricular function and positive pressure ventilation in clinical practice: from hemodynamic subsets to respirator settings. Intensive Care Med 2003, 29:1426-1434.

122. Nanas S, Magder S: Adaptations of the peripheral circulation to PEEP. Am Rev Respir Dis 1992, 146:688-693.

123. Lemaire F, Teboul J-L, Cinotti L, Giotto G, Arbrouk F, Steg G, Macquin Ml: Acute left ventricular dysfunction during unsuccessful weaning from mechanical ventilation. Anesthesiology 1988, 69:171-179. 